\title{
The Influence of Heat Treatment on Uniaxial Elongational Flow Behavior of PS/SBS Blends
}

\author{
Akihiro NishIOKA, Akinari MineGISHI, Tatsuhiro TAKAHASHI, Tomonori KoDA, \\ Yuichi MasubuCHI, Jun-ichi TAKIMOTO, and Kiyohito KoYAMA* \\ Department of Polymer Science and Engineering, \\ Yamagata University, 4-3-16, Yonezawa 992-8510, Japan \\ (Received: March 14, 2006)
}

\begin{abstract}
Uniaxial elongational flow behavior was examined for polystyrene(PS)/styrene-butadiene-styrene(SBS) triblock copolymer by using a Meissner type rheometer under uniaxial elongational flow at constant strain rates. The mixtures of PS and SBS were prepared by means of a solution blending method. Pure PS did not exhibit strain-hardening. Elongational viscosity was quite similar among the mixtures of PS/SBS without heat treatment. However, large enhancement of strain-hardening was observed for PS/SBS blends treated at temperatures higher than $220^{\circ} \mathrm{C}$, and the magnitude of enhancement reached ten times or more. To analyze the cause of the enhancement of strain-hardening, we examined pure SBS itself using a combination of uniaxial elongation and FT-IR spectroscopy. Change in uniaxial elongational flow behavior, i.e., from strain-softening to strain-hardening, was observed corresponding to heat treatment temperatures. From FT-IR spectroscopy of SBS treated at various temperatures, the correlation between enhancement of strain-hardening and crosslinking of butadiene was obtained. From shear stress relaxation measurement of PS/SBS(90/ 10) treated at $260{ }^{\circ} \mathrm{C}$ for $60 \mathrm{~min}$, convergence of relaxation modulus was observed in a strain range of $\gamma \geqq 2$ at long times. Thus, the increase of strain-hardening of PS/SBS blends treated at high temperatures is likely to result from affine deformation of crosslinked SBS component.
\end{abstract}

Key words: Uniaxial elongational viscosity / Strain-hardening / Styrene-butadiene-styrene block polymer / Crosslinking

\section{INTRODUCTION}

In most of researches on melt rheology of two constituent polymer blends, rapid increase of elongational viscosity at large strains, which is referred to as strain-hardening in uniaxial elongation, is intermediate between that of each component. ${ }^{1)}$ On the other hand, the rheological property of homopolymer(A) / homopolymer(B) / block copolymer is essentially different from the trend mentioned above. Utracki et al. reported uniaxial elongational flow behavior of a series of PS/LDPE blends with and without compatibilizer, SEB (hydrogenated poly(styrene-b-isoprene)). ${ }^{2)}$ Incorporation of $5 \mathrm{wt} \%$ SEB with PS/LDPE blends induced unexpected decrease of strain-hardening and increase of linear viscoelastic envelope(LVE). A similar finding was reported for PP/SBS/ $\operatorname{SMA}(65 / 20 / 15 \mathrm{wt} \%)$ blend. ${ }^{3)}$ It is conjectured that this finding is related to flow properties of SBS triblock copolymer melts since they show strain-softening under uniaxial elongational flow.

* To whom correspondence should be addresse

E-mail: koyama@yz.yamagata-u.ac.jp, TEL: +81 238-26-3055, FAX: +81 238-26-3411
Taking these things mentioned above into account, we can expect the mixture of SBS and homopolymer will show the decrease of strain-hardening under elongational flow. Thus, we examined uniaxial elongational viscoisty of PS/SBS blend prepared by using a solution blending method. However, elongational flow behavior was not changed by adding SBS. Subsequently, PS/SBS blends were treated at high temperatures for the purpose of crosslink of SBS since the existence of highly crosslinked butadiene particle in ABS is a cause of a decrease of strain-hardening as reported by Takahashi et al. ${ }^{5)}$ However, large enhancement of strainhardening was observed for the PS/SBS blends and magnitude of strain-hardening reached ten times in comparison to that of PS matrix. This novel elognational rheology has not been observed for any other PS polymers before. Thus, understanding the cause of the novel elongational rheology is quite interesting for us in order to control the elongational rheology with a small mass fraction of component.

In the present work, the effects of SBS content and heat treatment condition on uniaxial elongational flow behavior were investigated. The amount of SBS was changed from 0 to 
$10 \mathrm{wt} \%$. The nonlinear properties are discussed in terms of uniaxial viscosity measurement and FT-IR spectroscopy of pure SBS with different heat treatment conditions, in addition to shear stress relaxation measurement and TEM observations of PS/SBS with or without heat treatment.

\section{EXPERIMENTAL}

\subsection{Materials}

Polystyrene (PS666, $M_{\mathrm{w}}=220 \mathrm{k}, M_{\mathrm{w}} / M_{\mathrm{n}}=2.0$ ) kindly supplied from A\&M Styrene Co., Ltd., styrene-butadienestyrene(SBS) triblock copolymer(SBS, $M_{\mathrm{w}}=80 \mathrm{k}, M_{\mathrm{w}} / M_{\mathrm{n}}=1.3$, $\mathrm{S} / \mathrm{B} / \mathrm{S}=20 / 60 / 20 \mathrm{wt} \%$, lamella structure) and nearly monodispersed polybutadiene( $\left.\mathrm{PB}, M_{\mathrm{w}}=50 \mathrm{k}, M_{\mathrm{w}} / M_{\mathrm{n}}=1.04\right)$ which were kindly supplied by Asahi Chemical Industry Co., Ltd. were used.

To make the mixture of PS and SBS, two samples were dissolved in tetrahydorofluen(THF) to make a $5 \mathrm{wt} \%$ solution. Then the solution was dried at room temperature and further dried at $120^{\circ} \mathrm{C}$ in a vacuum for $48 \mathrm{~h}$. The dried films were molded by using Mini Test Press-10 (Toyoseki Seisakusho Co., Ltd). This preparation method follows that in a previous work. ${ }^{6)}$ For PS and PS/SBS blends without annealing, the sample was heated under $10 \mathrm{MPa}$ at $180{ }^{\circ} \mathrm{C}$ and cooled gradually below $T_{\mathrm{g}}$. In cases of PS and PS/SBS blends with annealing, the samples were heated under $10 \mathrm{MPa}$ at high temperatures $\left(220,240\right.$, and $\left.260^{\circ} \mathrm{C}\right)$ for $60 \mathrm{~min}$ and cooled rapidly. Subsequently, the sample was heated to $140{ }^{\circ} \mathrm{C}$ and cooled gradually below $T_{\mathrm{g}}$ to prevent shrinkage during uniaxial elongational measurement. Each sample was dried in a vacuum at $80^{\circ} \mathrm{C}$ for $24 \mathrm{~h}$ to eliminate water. Samples used in this study were listed in Table I.

\subsection{Measurements}

The transient growth of uniaxial elongational viscosity was measured on thin slabs of material by using a new Meissner type elongational rheometer(Rheometrics, RME). A detailed description and discussion on the reliability of the elongational

Table I. Composition and heat treatment condition of samples

\begin{tabular}{ll}
\hline Composition & Heat treatment condition \\
\hline PS666 & none, $260^{\circ} \mathrm{C}$ for $60 \mathrm{~min}$ \\
\hline SBS & none, $220^{\circ} \mathrm{C}$ for $60 \mathrm{~min}$, \\
& $240^{\circ} \mathrm{C}$ for $60 \mathrm{~min}, 260^{\circ} \mathrm{C}$ for $60 \mathrm{~min}$ \\
\hline PS666/SBS(95/5) & none, $260^{\circ} \mathrm{C}$ for $60 \mathrm{~min}$ \\
\hline PS666/SBS(90/10) & none, $220^{\circ} \mathrm{C}$ for $60 \mathrm{~min}$, \\
& $240^{\circ} \mathrm{C}$ for $60 \mathrm{~min}, 260^{\circ} \mathrm{C}$ for $60 \mathrm{~min}$ \\
\hline PS666/PB(90/10) & $260^{\circ} \mathrm{C}$ for $60 \mathrm{~min}$ \\
\hline
\end{tabular}

rheometer were given by Meissner and Hostettler. ${ }^{11)}$ This device provides a sample with a constant elongational strain rate by gripping the sample between counter-rotating caterpillar tracks. The sample was both heated and suspended mechanically in a rising current of temperature-controlled nitrogen. The test sample is a sheet with dimensions of $0.5 \times 7 \times 60 \mathrm{~mm}^{3}$. Measurement temperatures were $140{ }^{\circ} \mathrm{C}$ and $180^{\circ} \mathrm{C}$. The strain rates were $0.5,0.2,0.1,0.05,0.02$ and $0.01 \mathrm{~s}^{-1}$, and uniformity in deformation of the sample was checked by direct video imaging. The data in cases of nonuniformity of the sample, apparent slipping of sample between counter-rotating caterpillar tracks, and lower limitation of elongational force were discarded.

Nonlinear stress relaxation experiments (Rheometrics, ARES) were performed at $180{ }^{\circ} \mathrm{C}$ by applying different stepshear strains, $0.01,0.1,0.3,0.5,1,2,3$ and 4 in a nitrogen atmosphere. The used geometry was cone-and-plate with a diameter of $25 \mathrm{~mm}$. Data reproducibility of shear relaxation modulus was checked by applying both clockwise and counterclockwise step-shear strains. Fracture of sample at the edge was not detected after the experiment when the strain was below 4 .

\section{RESULTS AND DISCUSSION}

\subsection{Uniaxial Elongational Flow Behavior of PS/SBS Blends}

Figures 1(a) (d) show uniaxial elongational viscosity at $140{ }^{\circ} \mathrm{C}$ for PS666, SBS, PS666/SBS(95/5) and PS666/ $\operatorname{SBS}(90 / 10)$ at $140{ }^{\circ} \mathrm{C}$ without heat treatment, respectively. Both linear viscoelastic envelope(LVE, elongational viscosity at small strain) and strain-hardening were not changed by an incorporation of SBS up to $10 \mathrm{wt} \%$. Figures 2 (a) (c) show uniaxial elongational viscosity at $180{ }^{\circ} \mathrm{C}$ for PS666, PS666/ SBS(95/5) and PS666/SBS(90/10) without heat treatment, respectively. LVE and strain-hardening were not changed by incorporating SBS, either. According to the result of complex viscosity measurement for PS666 and SBS at frequencies of $0.1 \sim 100 \mathrm{rad} / \mathrm{s}$ at $140{ }^{\circ} \mathrm{C}$ and $180^{\circ} \mathrm{C}$, the complex viscosity of SBS was slightly lower than that of PS666 at both temperatures. This result indicates that elongational flow property should not change by blending SBS with PS666.

Figure 3(a) shows uniaxial elongational viscosity of PS666(with a heat treatment at $260{ }^{\circ} \mathrm{C}$ for $60 \mathrm{~min}$ ) at $180{ }^{\circ} \mathrm{C}$. In comparison to PS666 without heat treatment, LVE was slightly decreased due to thermal degradation, but strainhardening was not changed. The result suggests that branching and high molecular weight component of PS was not 
generated. Figures 3(b) and (c) show uniaxial elongational viscosity of PS666/SBS(95/5) and PS666/SBS(90/10)(with a heat treatment at $260^{\circ} \mathrm{C}$ for $\left.60 \mathrm{~min}\right)$ at $180{ }^{\circ} \mathrm{C}$. Enhancement of strain-hardening was observed even at a concentration of $5 \mathrm{wt} \% \mathrm{SBS}$, and the magnitude of strain-hardening reached five to ten times at a Hencky strain of 2. Strain-hardening seems to become slightly stronger with decreasing strain rate. Existence of some heterogeneous structure might be suggested.

Figures 4(a) and (b) show uniaxial elongational viscosity of PS666/SBS(90/10, heat treatment at $220{ }^{\circ} \mathrm{C}$ for $60 \mathrm{~min}$ ) and
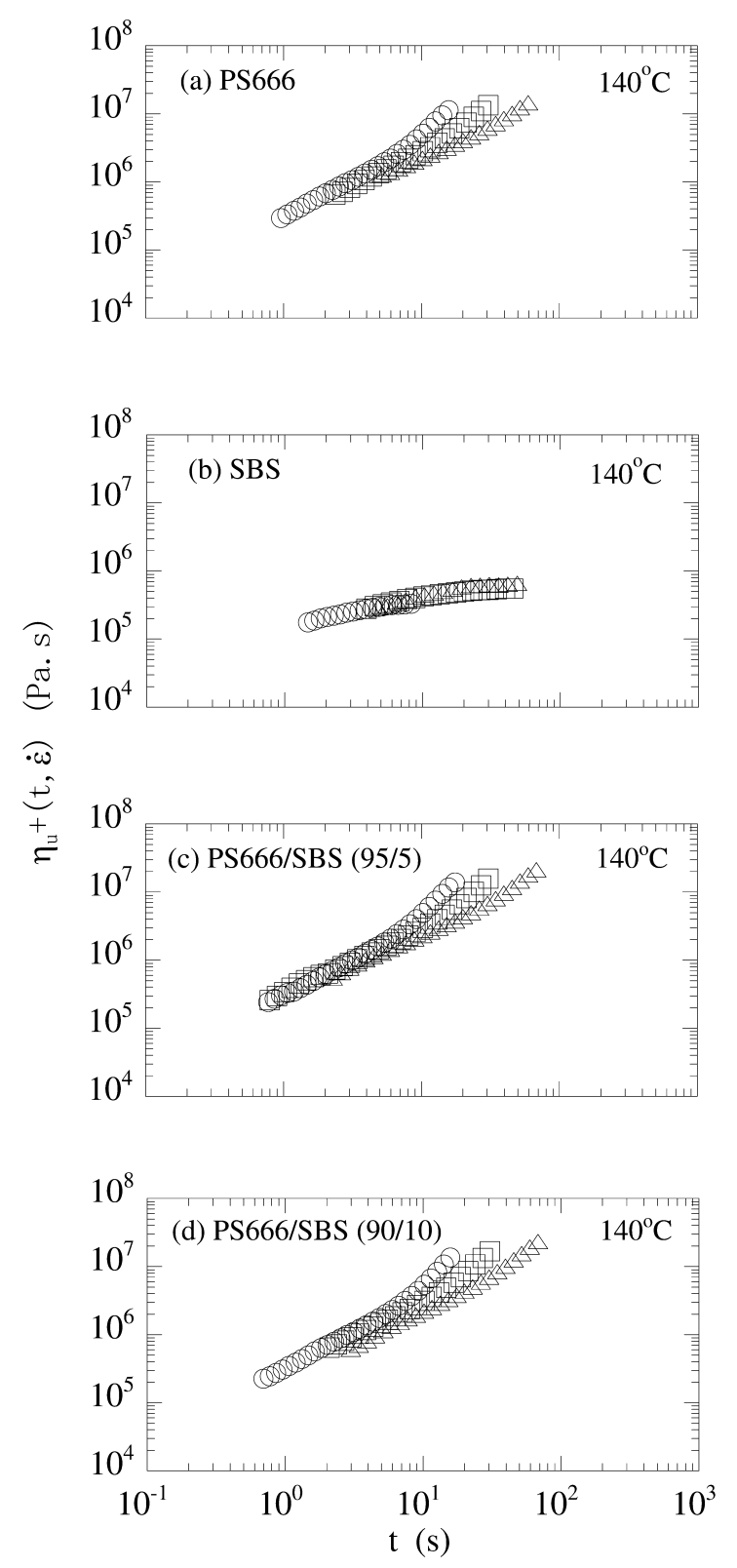

Fig. 1. Time-dependent uniaxial elongational viscosity of PS666, SBS and their blends at $140{ }^{\circ} \mathrm{C}$ at various constant strain rates $\left(\mathrm{s}^{-1}\right)$ : a for PS666 $(O) 0.2 ;(\square) 0.1 ;(\triangle) 0.05 ; \mathbf{b}$ for SBS $(O) 0.2 ;(\square) 0.05$; $(\triangle) 0.02$; $\mathbf{c}$ for PS666/SBS $(95 / 5)(O) 0.2 ;(\square) 0.1 ;(\triangle) 0.05 ; \mathbf{d}$ for PS666/SBS(90/10) (O)0.2; $(\square) 0.1 ;(\triangle) 0.05$.
PS666/SBS(90/10, heat treatment at $240{ }^{\circ} \mathrm{C}$ for $\left.60 \mathrm{~min}\right)$, respectively. In comparison to PS666/SBS(90/10) without heat treatment, enhancement of strain-hardening was observed for each blend. LVEs of PS666/SBS(90/10, heat treatment at $220^{\circ} \mathrm{C}$ for $60 \mathrm{~min}$ ) and PS666/SBS(90/10, heat treatment $240^{\circ} \mathrm{C}$ for $60 \mathrm{~min}$ ) were almost equivalent each other. The magnitude of strain-hardening became larger with increasing heat treatment temperature and it reached ten times or more up to a Hencky strain of 3.

For every blend, strain rate dependence of strain-hardening was relatively small over a wide range of strain rate. In the case of homopolymer melts, strain-hardening usually becomes weaker with decreasing strain rate. ${ }^{7)}$ On the other hand, some heterogeneous polymeric systems show anomalous strain rate
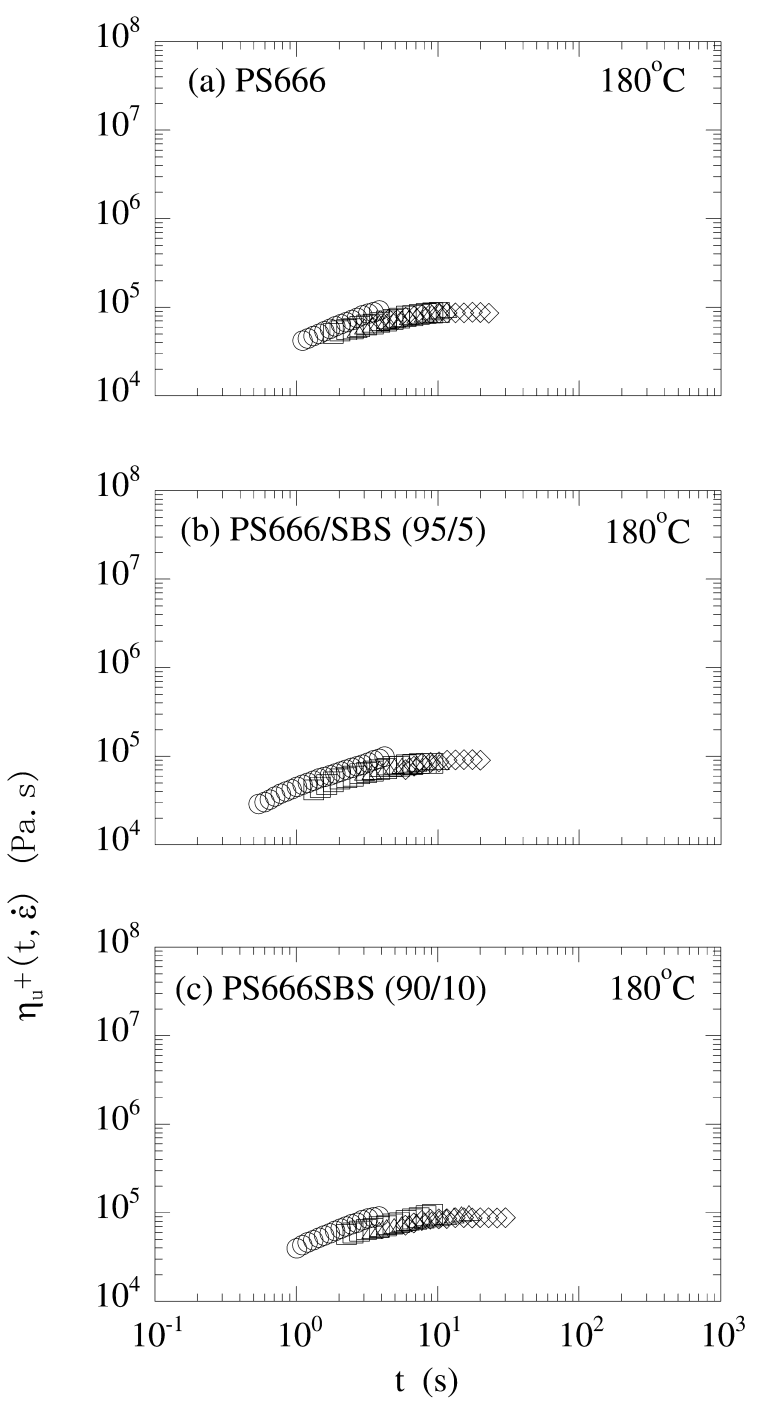

Fig. 2. Uniaxial elongational viscosity of PS666/SBS blends at $180^{\circ} \mathrm{C}$ at various constant strain rates $\left(\mathrm{s}^{-1}\right)$ : a for PS666 $(\mathrm{O}) 0.5 ;(\square) 0.2$; $(\triangle) 0.1 ;(\diamond) 0.05 ; \quad$ b for $\operatorname{PS} 666 / \operatorname{SBS}(95 / 5)$ (O) $0.5 ; \quad(\square) 0.2$; $(\triangle) 0.1 ;(\diamond) 0.05 ;$ c for $\operatorname{PS} 666 / \operatorname{SBS}(90 / 10)(\bigcirc) 0.5 ;(\square) 0.2$; $(\triangle) 0.1 ;(\diamond) 0.05$. 
dependence of strain-hardening. ${ }^{8-11)}$ Elongational viscosity of rubber shows independence of strain-hardening from strain rate since stress-strain curves at various strain rates converge on one line. The mechanism of enhancement of strainhardening is presumably related to elasticity of SBS. This will further be discussed in the next section.

\subsection{Uniaxial Elongational Flow Behavior of SBS}

In order to understand the role of SBS on strain-hardening enhancement of PS/SBS treated at high temperatures, we measured elongational viscosity of pure SBS with various heat treatment conditions. Figure 5(a) shows uniaxial elongational viscosity of SBS(heat treatment at $220^{\circ} \mathrm{C}$ for $60 \mathrm{~min}$ ) at $140{ }^{\circ} \mathrm{C}$. Very weak strain-softening was observed at every
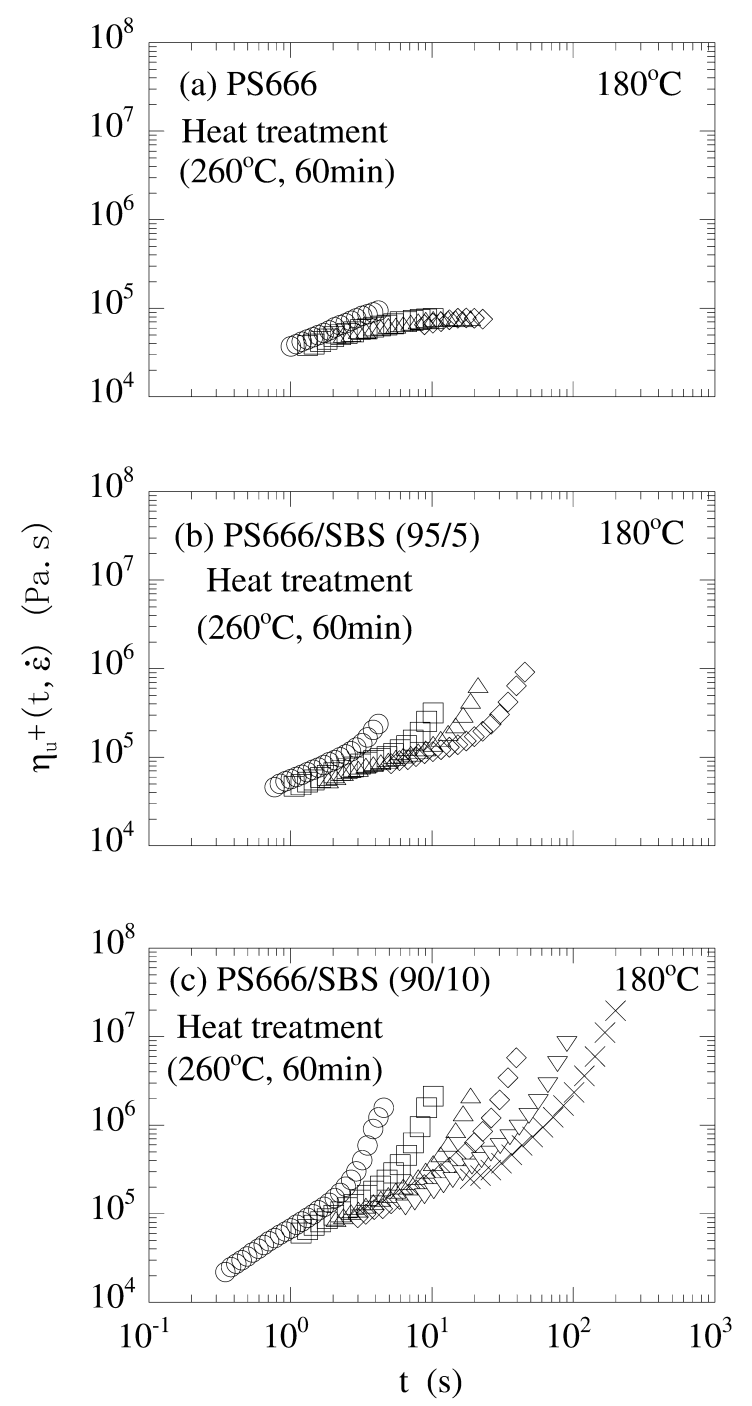

Fig. 3. Time-dependent uniaxial elongational viscosity of PS666/SBS blends treated at $260{ }^{\circ} \mathrm{C}$ for 60 min measured at $180{ }^{\circ} \mathrm{C}$ under a condition of various constant strain rates $\left(\mathrm{s}^{-1}\right)$ : a for PS666 $(\bigcirc) 0.5 ; \quad(\square) 0.2 ; \quad(\triangle) 0.1 ; \quad(\diamond) 0.05 ; \quad$ b for $\operatorname{PS} 666 / \operatorname{SBS}(95 / 5)$ $(\bigcirc) 0.5 ;(\square) 0.2 ;(\triangle) 0.1 ;(\diamond) 0.05 ;$ c for $\operatorname{PS} 666 / \operatorname{SBS}(90 / 10)$ (O) $0.5 ;(\square) 0.2 ;(\triangle) 0.1 ;(\diamond) 0.05 ;(\nabla) 0.02 ;(\times) 0.01$. strain rate in the range of experimental conditions. Figures 5(b) and (c) show uniaxial elongational viscosity of SBS(heat treatment at $240{ }^{\circ} \mathrm{C}$ for $60 \mathrm{~min}$ ) and SBS(heat treatment at $260{ }^{\circ} \mathrm{C}$ for $60 \mathrm{~min}$ ), respectively. SBS(heat treatment at $220^{\circ} \mathrm{C}$ for $60 \mathrm{~min}$ ) also showed weak strain-softening and slight increase of LVE in comparison to that of SBS without heat treatment. These strain-softenings are attributable to interlayer slippage between PS block chains and PB block chains at large strains because the molecular weight of PS block chain is slightly smaller than entanglement molecular weight of PS(approximately 18,000 g/mol). ${ }^{12)}$ On the contrary, SBS(heat treatment at $240{ }^{\circ} \mathrm{C}$ for $60 \mathrm{~min}$ ) and SBS(heat treatment at $260{ }^{\circ} \mathrm{C}$ for $60 \mathrm{~min}$ ) exhibited dramatic enhancement of strainhardening at every strain rate in the range of experimental conditions. The magnitude of strain-hardening and the values of LVE were in order of the height of heat treatment temperature. If the lamella structure is kept, SBS(heat treatment at $240{ }^{\circ} \mathrm{C}$ for $60 \mathrm{~min}$ ) and SBS(heat treatment at $260{ }^{\circ} \mathrm{C}$ for $60 \mathrm{~min}$ ) should exhibit strain-softening. However, the experimental data does not support this idea. Lamella structure may be changed by annealing at temperatures higher than $240{ }^{\circ} \mathrm{C}$. The structural change can be one of the cause of

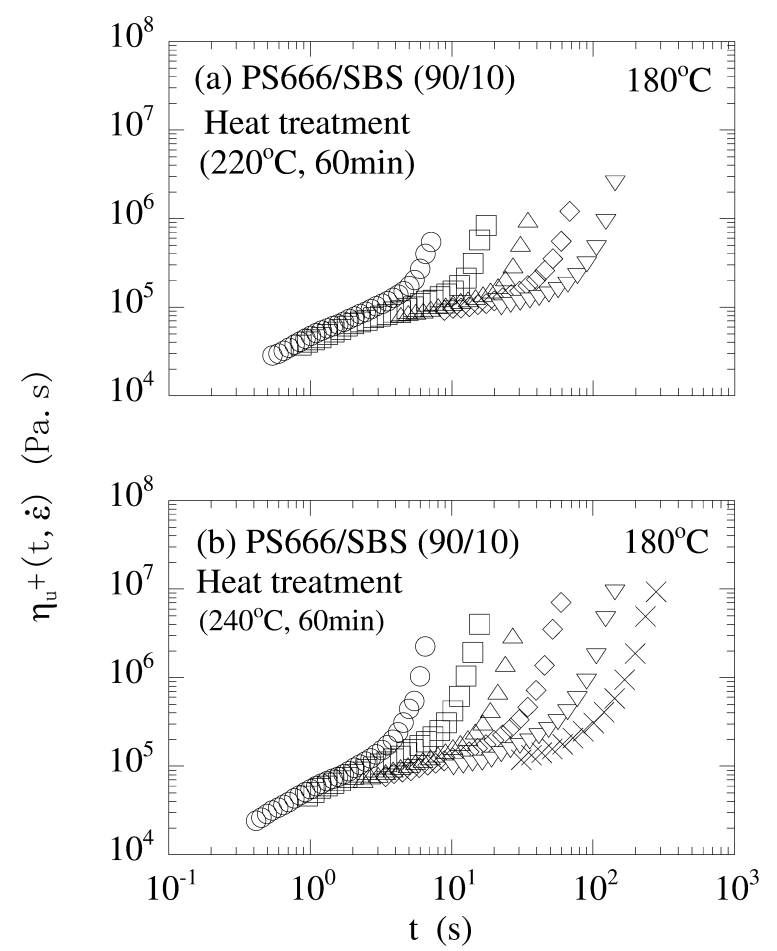

Fig. 4. Time-dependent uniaxial elongational viscosity of PS666/ $\operatorname{SBS}(90 / 10)$ treated a at $220^{\circ} \mathrm{C}$ for $60 \mathrm{~min}$; b at $240{ }^{\circ} \mathrm{C}$ for $60 \mathrm{~min}$. Both samples were measured at $180^{\circ} \mathrm{C}$ under a condition of various constant strain rates $\left(\mathrm{s}^{-1}\right)$ : a $(O) 0.5 ;(\square) 0.2 ;(\triangle) 0.1$ $(\diamond) 0.05 ;(\nabla) 0.02 ; \mathbf{b}(\bigcirc) 0.5 ;(\square) 0.2 ;(\triangle) 0.1 ;(\diamond) 0.05 ;(\nabla) 0.02$; ( $\times) .01$. 
enhancement of strain-hardening.

As another cause of the enhancement, crosslinking of PB in SBS is speculated. This is because (i) elongational viscosity increased even in LVE region, and (ii) for SBS(heat treatment at $260{ }^{\circ} \mathrm{C}$ for $60 \mathrm{~min}$ ), stress-strain curves at various strain rates converged on one line; They showed the elastic response. The origin of strain-hardening of the SBS will be analyzed by FT-IR spectroscopy in the following section.

\subsection{FT-IR Analysis of SBS with Various Heat Treatment Conditions}

FT-IR spectroscopy is a powerful tool to analyze what happens in a microstructure level. Figure 6(a) shows FT-IR spectra of SBS annealed in different conditions. The important
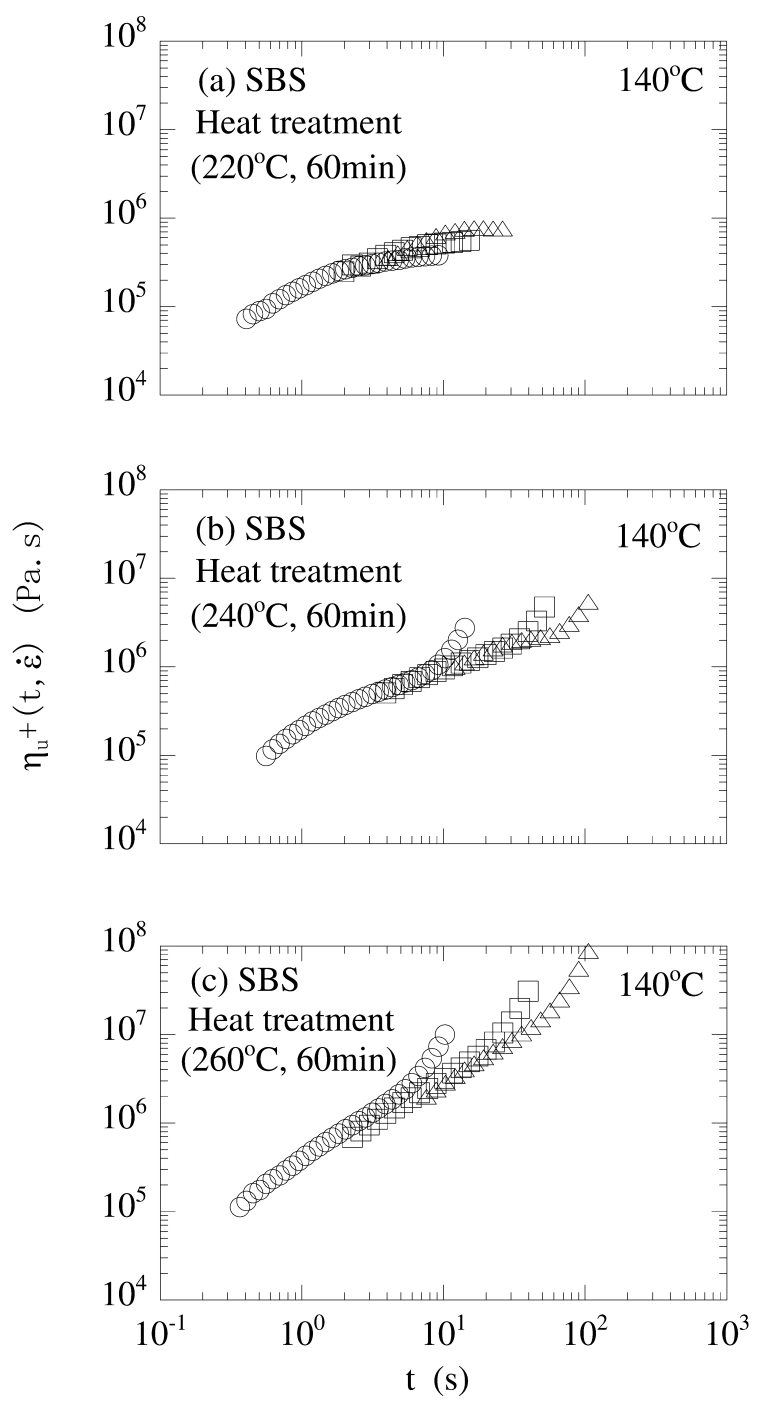

Fig. 5. Time-dependent uniaxial elongational viscosity of SBS treated a at $220{ }^{\circ} \mathrm{C}$ for $60 \mathrm{~min}$; b at $240{ }^{\circ} \mathrm{C}$ for $60 \mathrm{~min}$; c at $260{ }^{\circ} \mathrm{C}$ for $60 \mathrm{~min}$. Every sample was measured at $140{ }^{\circ} \mathrm{C}$ under a condition of various constant strain rates $\left(\mathrm{s}^{-1}\right)$ : a $(O) 0.2 ;(\square) 0.05 ;(\triangle) 0.02$; b $(\bigcirc) 0.2 ;(\square) 0.05 ;(\triangle) 0.02 ; \mathbf{c}(\bigcirc) 0.2 ;(\square) 0.05 ;(\triangle) 0.02$. peaks are denoted with arrows. The complete assignment of the bands can be found elsewhere. ${ }^{13)}$ There are several ways to analyze the data quantitatively; here, internal standard peak method was selected. ${ }^{14)}$ According to TGA measurement, PS was thermally stable even at $260{ }^{\circ} \mathrm{C}$ for $2 \mathrm{~h}$. Thus the peak at $1492 \mathrm{~cm}^{-1}$ derived from phenyl group in PS was adopted as representative. Bands derived from PB are $966 \mathrm{~cm}^{-1}$ (trans-1,4), $912 \mathrm{~cm}^{-1}$ (trans-1,2), $670 \mathrm{~cm}^{-1}\left(\right.$ cis-1,4), respectively. ${ }^{15)}$ The peaks at $966 \mathrm{~cm}^{-1}$ and $912 \mathrm{~cm}^{-1}$ were not observed with PS, which made it possible to follow the influence of double bonding of PB. However, the peak at $670 \mathrm{~cm}^{-1}$ was not observed. ${ }^{15)}$ Absorbance ratios of $966 \mathrm{~cm}^{-1} / 1492 \mathrm{~cm}^{-1}$ and $912 \mathrm{~cm}^{-1} / 1492 \mathrm{~cm}^{-1}$ for all samples are obtained. Then, these data were further normalized by those of SBS without annealing. These values suggest amounts of carbon-carbon double bonds of trans-1,4 PB and trans-1,2 PB surviving in SBS. In other words, these values indicate what percentage of trans-1,4 PB and trans-1,2 PB were exhausted to make crosslinking in SBS.

Figure 6(b) shows the absorbance ratios of $966 \mathrm{~cm}^{-1} / 1492 \mathrm{~cm}^{-1}$ (trans-1,4 PB) and $912 \mathrm{~cm}^{-1} / 1492 \mathrm{~cm}^{-1}$ (trans-1,2 PB) plotted against heat treatment temperature. It was clearly seen that the
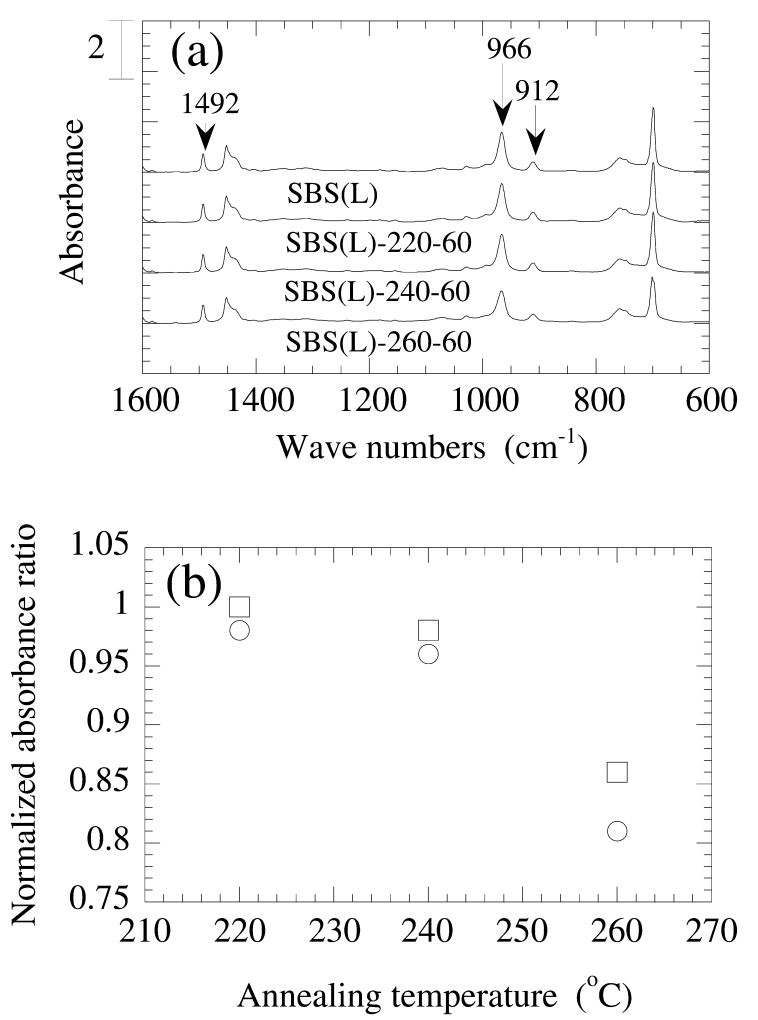

Fig. 6. a FT-IR spectra of SBS treated with various conditions. The spectra are shifted vertically to distinguish them easily. b normalized absorbance ratio plotted against treatment temperature: (O) $966 \mathrm{~cm}^{-1} / 1492 \mathrm{~cm}^{-1}$; (口) $912 \mathrm{~cm}^{-1} / 1492 \mathrm{~cm}^{-1}$. 
heat treatment temperature affected the absorbance ratio and the degree of decrease was in order of the height of heat treatment temperature. The degree of decrease in carboncarbon double bonds at trans-1,4 PB was higher than that of trans-1,2 PB at every annealing temperature. We conjectured the opposite results because trans-1,2 PB had carbon-carbon double bonds at side chains, which would result in larger decrease of carbon-carbon double bonds than those of trans-1,4 PB. But actually, such a tendency was not observed. The position of carbon-carbon double bonds will not possibly be so important for crosslinking reaction.

Now there still exists another reaction of decrease of carboncarbon double bonds at PB in SBS, i.e. thermal degradation. At present, it is impossible to exclude the effect of thermal degradation even by combining FT-IR with TGA analysis. ${ }^{16)}$ However, the results of elongational viscosity shown in Fig. 5(a) (c) suggest that the influence of thermal degradation and oxidation is small, while crosslinking reaction is dominant during heat treatment at high temperatures. Therefore, the enhancement of LVE and strain-hardening was induced by crosslinking of PB in SBS.

\subsection{Comparison of PS/SBS Blend and PS/PB Blend on Strain-Hardening}

Cross-linked butadiene in SBS enhanced strain-hardening under uniaxial elongational flow. It is expected that this also leads to enhancement of strain-hardening for PS/SBS blends treated at high temperatures. Then, if cross-linked polybutadiene(PB) is blended into PS, is the strain-hardening observed in a uniaxial elongational flow? The comparison of the data can give the answer for the role of PS block chains in SBS. Molecular weight of PB was almost the same as that of butadiene block in SBS. The mixture of PS and PB was prepared using the same method as described in the experimental section.

Figure 7 shows uniaxial elongational viscosity of PS666/ $\mathrm{PB}\left(90 / 10\right.$, heat treatment at $260^{\circ} \mathrm{C}$ for $\left.60 \mathrm{~min}\right)$ at $180^{\circ} \mathrm{C}$. LVE became larger than that of PS666 and the test sample was suddenly broken at around a Hencky strain of 1, which led to no strain-hardening. The observation of deformation of test sample during elongation showed that necking was generated at a part of test sample and it propagated further, which resulted in the rupture of the test sample. Similar behaviors were reported for immiscible polymer blends and filler dispersed polymeric systems. ${ }^{17-19)}$

On the contrary, for PS666/SBS(90/10, heat treatment at $260{ }^{\circ} \mathrm{C}$ for $60 \mathrm{~min}$ ), the rupture of sample was not observed.
Instead, apparent slippage between catapiller and sample was observed at around a Hencky strain of 2.5. The different features of the elongation of the samples surprised us because there was a macrophase structure both for PS666/SBS and PS666/PB. It seems reasonable for us to think that the miscibility of PS and SBS is better than that of PS and PB. The better miscibility of PS and SBS contributes to the enhancement of strain-hardening.

\subsection{Nonlinear Stress Relaxation in Shear of PS/SBS Blends}

In order to speculate the degree of deformation of SBS in PS/SBS at high temperatures, we accomplished a stress relaxation measurement. Figures $8(\mathrm{a}) \sim(\mathrm{c})$ show shear stress relaxation modulus of PS666(heat treatment at $260{ }^{\circ} \mathrm{C}$ for $60 \mathrm{~min}), \mathrm{PS} 666 / \mathrm{SBS}\left(95 / 5\right.$, heat treatment at $260^{\circ} \mathrm{C}$ for $60 \mathrm{~min}), \mathrm{PS} 666 / \mathrm{SBS}\left(90 / 10\right.$, heat treatment at $260{ }^{\circ} \mathrm{C}$ for $60 \mathrm{~min}$ ) at $180^{\circ} \mathrm{C}$, respectively. For every sample, when strain $\gamma$ was less than 0.5 , relaxation modulus did not depend on strain; linear relaxation modulus appeared. When $\gamma \geqq 1$, relaxation modulus at a fixed time decreased with increasing strain. For PS666(heat treatment at $260{ }^{\circ} \mathrm{C}$ for $60 \mathrm{~min}$ ), the curves obtained at various strains could be superposed by vertical shifts in the time range covered in this experiment. This relationship holds for many polymer liquids. ${ }^{20)}$

In case of PS666/SBS(90/10, heat treatment at $260{ }^{\circ} \mathrm{C}$ for $60 \mathrm{~min}$ ), the relaxation curves are essentially different from those of PS666(heat treatment at $260{ }^{\circ} \mathrm{C}$ for $60 \mathrm{~min}$ ) and PS666/SBS(95/5, heat treatment at $260{ }^{\circ} \mathrm{C}$ for $60 \mathrm{~min}$ ); there clearly exist two relaxation modes. The relaxation at short times was derived from entanglement relaxation due to the matrix PS chains because the relaxation modulus at each strain was very similar to those of PS666(heat treatment at $260{ }^{\circ} \mathrm{C}$ for $60 \mathrm{~min}$ ) at short times less than several seconds. The other

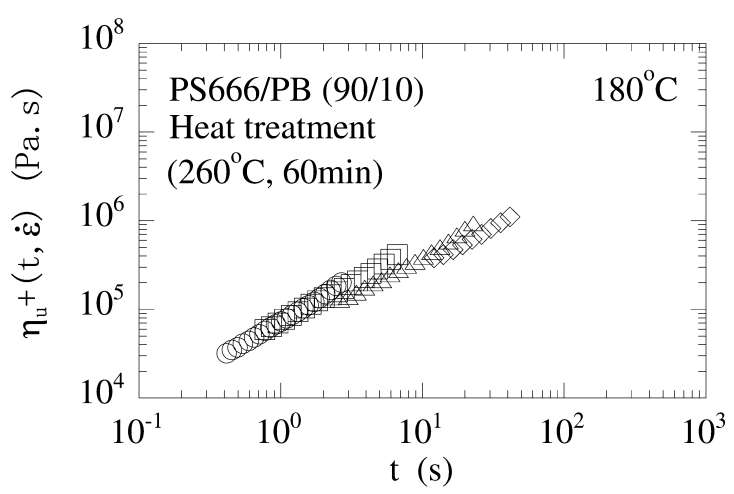

Fig. 7. Time-dependent uniaxial elongational viscosity of PS666/PB(90/ 10) treated at $260{ }^{\circ} \mathrm{C}$ for $60 \mathrm{~min}$ measured at $180{ }^{\circ} \mathrm{C}$ under various constant strain rates $\left(\mathrm{s}^{-1}\right)$ : $(\mathrm{O}) 0.5 ;(\square) 0.2 ;(\triangle) 0.1$; $(\diamond) 0.05$. 
relaxation at longer times was probably due to the crosslinked SBS having long relaxation times because relaxation modulus curves converged with one another at long times and the tendency became visibly clearer at $\gamma \geqq 2$. This convergence indicates that SBS component deforms affinely.

In case of PS666/SBS $\left(95 / 5\right.$, heat treatment at $260{ }^{\circ} \mathrm{C}$ for $60 \mathrm{~min}$ ), the relaxation modulus at each strain was basically similar to that of PS666(heat treatment at $260^{\circ} \mathrm{C}$ for $60 \mathrm{~min}$ ). Looking at the data very carefully, we could see the curves began to converge slightly at long times. However, the data at longer times scale could not be obtained due to the lower limitation of torque. In the time range covered in this experiment, the curves obtained at various strains could be
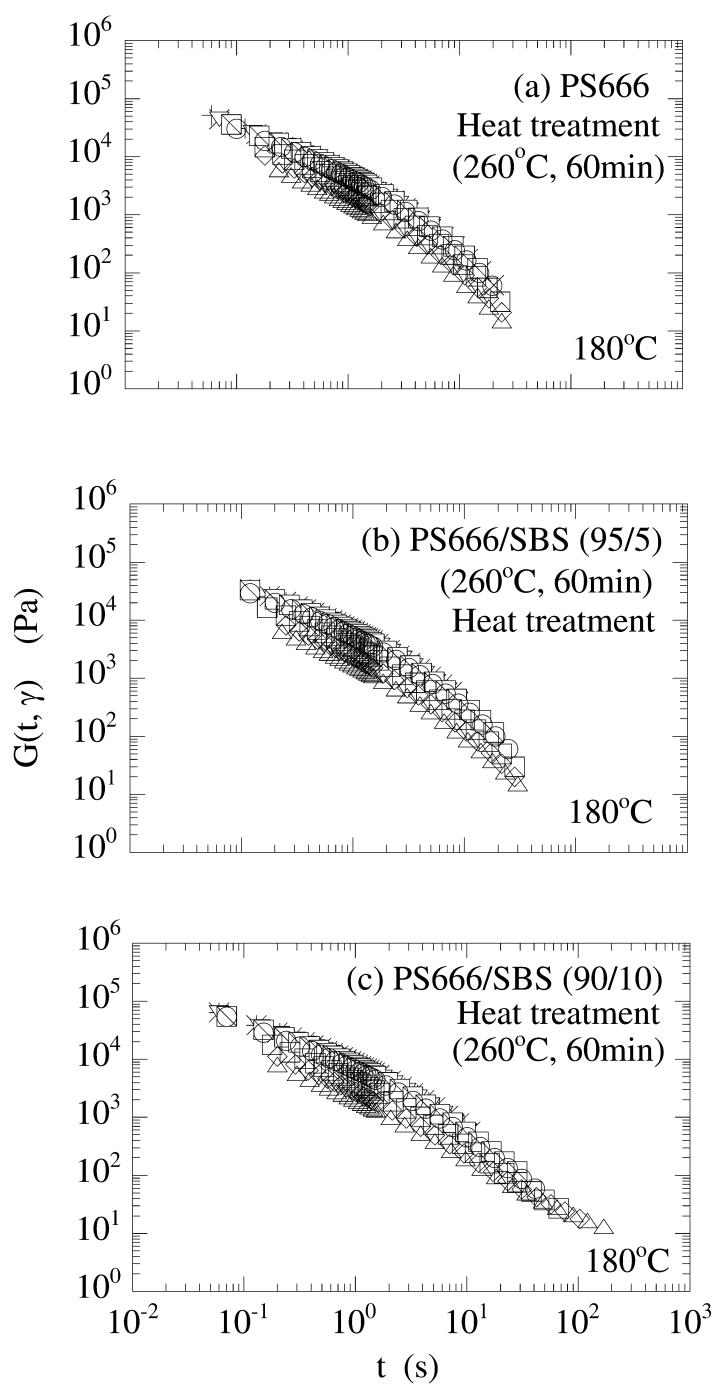

Fig. 8. Shear stress relaxation modulus of: a PS666 treated at $260{ }^{\circ} \mathrm{C}$ for $60 \mathrm{~min}$; b PS66/SBS(95/5) treated at $260{ }^{\circ} \mathrm{C}$ for $60 \mathrm{~min}$; c PS66/ $\operatorname{SBS}(90 / 10)$ treated at $260{ }^{\circ} \mathrm{C}$ for 60 min measured at $180{ }^{\circ} \mathrm{C}$ at different step shear strains: a $(+) 0.01 ;(\times) 0.1 ;(\nabla) 0.2 ;(\square) 0.5$; $(\bigcirc) 1 ;(\square) 2 ;(\diamond) 3 ;(\triangle) 4 ; \mathbf{b}(+) 0.01 ;(\times) 0.1 ;(\nabla) 0.2 ;(\square) 0.5$; $(\bigcirc) 1 ;(\square) 2 ;(\diamond) 3 ;(\triangle) 4 ;$ c $(+) 0.01 ;(\times) 0.1 ;(\nabla) 0.2 ;(\square) 0.5$; $(\bigcirc) 1 ;(\square) 2 ;(\diamond) 3 ;(\triangle) 4$. superposed by vertical shifts.

Figure 9 shows damping function $h(\gamma)$ for samples with various strains. The solid line represents the prediction from Doi-Edwards theory. ${ }^{21)}$ The experimental data deviated from Doi-Edwards prediction each other. This is derived from MWD. Damping functions of each sample at short times were slightly stronger as the content of SBS was higher. Damping function of PS666/SBS(90/10, heat treatment at $260{ }^{\circ} \mathrm{C}$ for $60 \mathrm{~min}$ ) at long times could not be determined since data of relaxation modulus at small strains were not obtained. However, as mentioned above, relaxation moduli converged at long times and at large strains, indicating affine deformation of crosslinked SBS component.

\subsection{Morphology of PS/SBS Blends before Elongation}

In order to follow the dispersed state SBS into PS matrix before and after heat treatment at high temperatures, we accomplished TEM observation. Figures 10(a) and (b) show

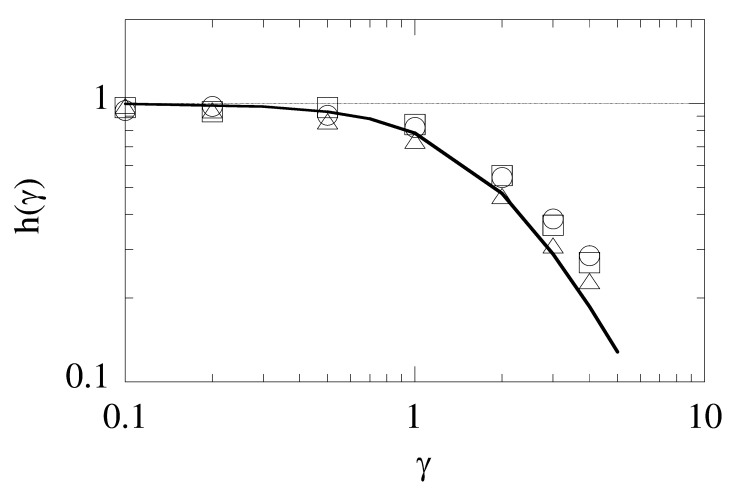

Fig. 9. Damping functions from shear stress relaxation modulus of PS666/SBS blends treated at $260{ }^{\circ} \mathrm{C}$ for $60 \mathrm{~min}$ (O)PS666; (口)PS666/SBS(95/5); ( $\triangle$ )PS666/SBS(90/10). The solid line represents damping function of polymer with narrow MWD from Doi-Edwards theory.

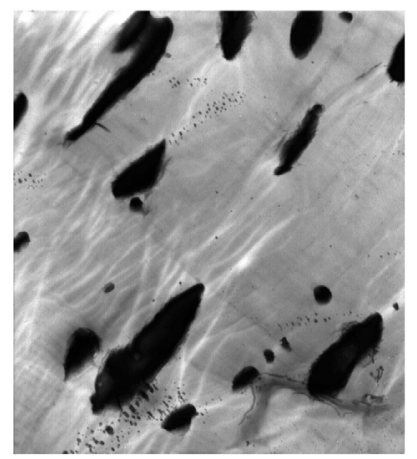

(a)

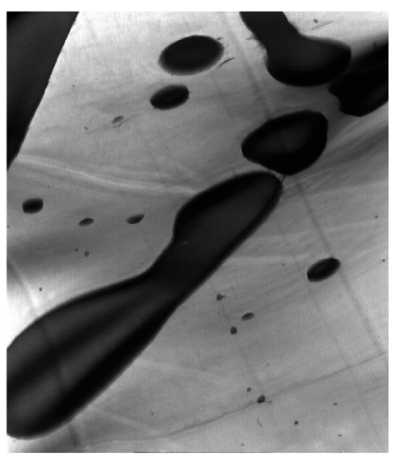

(b) $\overline{1 \mu \mathrm{m}}$

Fig. 10. TEM micrographs of a PS666/SBS(90/10) (left side) and b PS666/SBS(90/10) treated at $260{ }^{\circ} \mathrm{C}$ for $60 \mathrm{~min}$ (right side) before elongation. 
TEM micrographs of PS666/SBS(90/10) without heat treatment before elongation and PS666/SBS(90/10, heat treatment at $260{ }^{\circ} \mathrm{C}$ for $60 \mathrm{~min}$ ) before elongation, respectively. As seen in these figures, both PS/SBS blends have macroscopic phase separation. The reason of macroscopic phase separation is that chains of PS matrix are longer than PS block chains in SBS: beyond the limit of solubilization. ${ }^{22-24)}$ Size distributions of SBS domain were $1 \sim 3 \mu \mathrm{m}$ for PS666/SBS(90/10) without heat treatment and $1 \sim 8 \mu \mathrm{m}$ for PS666/SBS(90/10, heat treatment at $260{ }^{\circ} \mathrm{C}$ for $60 \mathrm{~min}$ ), respectively. The interesting point is that coarsening of macroscopic SBS domains was partly observed by heat treatment at high temperature. Low viscosity of PS may have led to agglomeration of domains during heat treatment.

\subsection{Mechanism of Enhancement of Strain-Hardening for PS/SBS Blends Treated at High Temperatures}

For the enhancement of strain-hardening, it is considered that significant stretch of crosslineked SBS component is considered to be indispensable. According to the results illustrated above, affine deformation of crosslinked SBS component during elongation is the cause of enhancement of strain-hardening of PS/SBS treated at high temperatures. Here, we consider two mechanisms to explain the enhancement of strain-hardening. One is deformation of SBS domain, and the other is deformation of crosslinked SBS chains dissolved microscopically into PS matrix.

At first, possibility of deformation of SBS domain is discussed. For acrylonitrile-butadiene-styrene(ABS), Takahashi et al. reported the effect of hardness (degree of crosslinking) of butadiene on uniaxial elongational viscosity. ${ }^{5}$ ) ABS has a two-phase structure where butadiene particles grafted with AS are dispersed into AS matrix. They found that deformation of a butadiene particle was quite sensitive to its hardness(degree of crosslinking). Hard butadiene particles made strain-hardening weaker. Degree of crosslink of butadiene particle does not contribute to the enhancement of strain-hardening even when butadiene particles are deformed by elongation. However, for the present PS/SBS blends treated at high temperatures, enhancement of strain-hardening was observed. One difference in comparison to the non-heattreated samples is the size of domain. According to TEM micrographs in Fig.10, the size of domain for heat treated samples is larger than for non-heat-treated samples. This size growth was mainly caused by agglomeration of domains at heat treatment temperature. One reason of the strain hardening is the deformation of these large size domains. However, the deformation of domains is not so easy because of the rigidity increase of butadiene domain. Thus, we have to examine another source of the strain hardening.

We consider a second mechanism, that is the deformation of crosslinked SBS chains dissolved microscopically into PS matrix. Sugimoto et al. reported uniaxial and biaxial elongational flow behaviors of PP/UHMW-PE(99.6/0.4 and 99/1). ${ }^{10)}$ This sample has a domain structure according to TEM micrograph and the domain acts as a rigid particle. Nevertheless, the sample showed dramatic enhancement of strain-hardening and anomalous strain rate dependence of strain-hardening. They calculated strain-hardening using molecular constitutive equations given by Osaki et al. ${ }^{26)}$ borrowing the description of chain stretch and orientation of multi-branched polymer proposed by McLeish and Larson. ${ }^{25)}$ In the plot of reduced stress against Hencky strain for PP/UHMW-PE(99/1), the reduced stresses at various strain rates converged on a single value independent of strain rates at $\gamma \geqq 4$. In the experimental data, the extensional stress tended to converge at large strains, corresponding the calculation. Therefore, they suggested that a presence of effective PE chains dissolved microscopically into PP matrix is a source of the enhancement of strain-hardening under elongational flow. ${ }^{10)}$

From the work mentioned above, we consider that a phenomenon similar to that reported by Sugimoto et al. occurred for PS/SBS blends with heat treatments. The distinctive elongational flow behavior of PS/SBS treated at high temperatures presumably also results from significant stretch of crosslinked SBS chains dissolved microscopically into PS matrix. We also consider that this elongation of crosslinked SBS close to interfaces helps deformation of rigid butadiene domains. Hence, the stress of strain hardening is derived probably from significant stretch of both crosslinked SBS domains and crosslinked SBS chains dissolved microscopically into PS matrix.

\section{CONCLUSIONS}

The present study provided the following new findings:

1. Uniaxial elongational flow behavior of PS666/SBS(95/ $5,90 / 10$ ) blends was very similar to that of PS666 at both $140{ }^{\circ} \mathrm{C}$ and $180^{\circ} \mathrm{C}$. This was due to macroscopic phase separation and viscosity of SBS lower than that of PS matrix.

2. Uniaxial elongational flow behavior of $\mathrm{PS} / \mathrm{SBS}(90 / 10)$ blends treated at more than $220^{\circ} \mathrm{C}$ showed dramatic 
enhancement of strain-hardening, and PS/SBS(95/5) treated at $260{ }^{\circ} \mathrm{C}$ for $60 \mathrm{~min}$ also showed enhancement of strainhardening even at $5 \mathrm{wt} \%$ SBS. The magnitude of strainhardening reached ten times or more up to a Hencky strain of 3 , and it was in order of SBS content and heat treatment temperature.

3. For SBS treated at various temperatures, uniaxial elongational flow behavior was changed from strain-softening to strainhardening with increasing heat treatment temperature. The cause was identified as structural change and crosslinking of butadiene block chains in SBS from FT-IR spectrum analysis.

4. Shear stress relaxation of $\mathrm{PS} / \mathrm{SBS}(90 / 10)$ blends treated at $260{ }^{\circ} \mathrm{C}$ for $60 \mathrm{~min}$ showed convergence of relaxation moduli at long times when applied strain was more than 2 . This indicates affine deformation of crosslinked SBS component.

\section{Acknowledgenents}

We are grateful to Asahi Chemical Co., Ltd. for providing samples and helpful discussion. The authors would also like to thank Prof. Dr. K. Osaki (Kyoto University, Japan) for his valuable comments and suggestions.

\section{REFERENCES}

1) Utracki LA, Sammut P, Polym Engng Sci, 30, 1019(1990).

2) Utracki LA, "Polymer alloys and blends, thermodynamics and rheology", (1990), Hanser Publishers, New York.

3) Tanaka K, Koyama K, Watanabe J, Seni-Gakkaishi, 50, 1 (1994).

4) Takahashi T, Takimoto J, Koyama K, Mat Sci Res Int , 4, 97 (1998).

5) Takahashi T, Takimoto J, Koyama K, J Non-Newtonian Fluid Mech, 68, 259 (1997).
6) Takahashi T, Takimoto J, Koyama K, J Appl Polym Sci, 73, 757 (1999).

7) Takahashi M, Masuda T, Onogi S, Nihon Reoroji Gakkaishi, 11, 13 (1983).

8) Kobayashi M, Takahashi T, Takimoto J, Koyama K, Polymer 37, 3745 (1996).

9) Okamoto M, Morita S, Kim YH, Kotaka T, Tateyama H, Polymer, 41, 3887 (2000).

10) Sugimoto $M$, Masubuchi $Y$, Takimoto J, Koyama K, Macromolecules 34, 6056 (2001).

11) Sugimoto M, Suzuki $Y$, Hyun $K$, Ahn K H, Ushioda $T$, Nishioka A, Taniguchi T, Koyama K, Rheol Acta, in press.

12) Onogi S, Masuda T, Kitagawa K, Macromolecule, 3, 109 (1970).

13) Silverstein RM, Bassler GC, Morrill TC, "Spectrometric identification of organic compounds”, (1981), Wiley, New York.

14) Hamilton LF, Simpson SG, Ellis DW, “Calculations of analytical chemistry”, (1969), McGraw-Hill Book Company, London.

15) Krause S, Lu Z, Iskandar M, Macromolecules, 15, 1076 (1982).

16) Amdt KF, Richer A, Ludwig S, Zimmermann J, Kuckling D, Adler HJ, Acta Polym, 50, 383 (1999).

17) Meissner J, Makromol Chem Macromol Symp, 56, 25 (1992).

18) Takahashi T, Takimoto J, Koyama K, J Appl Polym Sci, 69, 1765 (1998).

19) Takahashi T, Takimoto J, Koyama K, Polymer Composites, 20, 357 (1999).

20) Osaki K, Rheol Acta, 32, 429 (1993).

21) Doi M, Edwards SF, "The theory of polymer dynamics", (1986), Oxford University, Oxford.

22) Hashimoto T, Tanaka H, Hasegawa H, Macromolecules, 23, 4378 (1990).

23) Lowenhaupt B, Hellmann GP, Polymer, 32, 1065 (1991).

24) Jeon KJ, Roe RJ, Macromolecules, 27, 2439 (1994).

25) McLeish TCB, Larson RG, J Rheol, 42, 81(1998).

26) Osaki K, Watanabe H, Inoue T, Nihon Reoroji Gakkaishi, 27, 63 (1999). 